\title{
Social and political processes in the context of contemporary communication technologies
}

\author{
Artysh Saryglar, Oleg Gonchar, and Sergey Chirun \\ Kemerovo State University, Krasnaya Str., 6, 650000 Kemerovo, Russia
}

\begin{abstract}
The article is devoted to the analysis of social and political processes in the aspect of modern technologies of political communication. In particular, the issue of stability of institutional development is touched upon in the context of innovative socio-political processes associated with the introduction of information digital technologies into public policy. The authors investigate current examples of the impact of these technologies on Russian political practices and suggest current areas of work with Internet communication technologies. The authors consider the information society as a global space for political communications, drawing their attention to new potential and real challenges and threats associated with the use of digital information arrays.
\end{abstract}

\section{Introduction}

All over the world, we observe a stable trend for the sustainable development of digitalization processes in the spheres of public, political and cultural life [1].

In the conditions of post-modernity, the line between politics and show is lost and politics is carnivalized. the postmodern "political carnival» unfolds in the «society of the spectacle». Here shows replace reality, form simulacra of reality and even create innovative hyperreality.

The updated political post-reality is radically transforming, thanks to the interpenetration and splicing of public policy and the digital communication sphere, as well as the successful robotization of online networks.

Digital communication provides a technical opportunity to take into account the individ ual characteristics of each user. Artificial intelligence studies digital traces, analyzes the nee ds and perceptions of users, interacts with them in their language in such a way that it is very difficult to distinguish it from a real interlocutor.

The post - reality in which humanity exists today makes it possible for technology corpo rations to collect a huge amount of diverse data about users. Analysts process this data using Big Data technologies and actively use it in political management. On the other hand, digitalization processes can have their dark side, manifested in cyberattacks, theft of funds, as well as cyber espionage.

The question of how to preserve privacy and at the same time ensure the safety and efficient operation of the state apparatus has been at the center of public discussion for many years. Therefore, states are improving legislative measures to protect personal data. At the same time, the vast majority of users are seriously concerned about this issue. Tracking and data processing technologies are developing at a rapid pace, regulation often does not have 
time to adapt to these changes. The transparency of surveillance technologies largely depends on government control and oversight mechanisms, which are not always effective enough.

A separate problem is the need for national laws to comply with international law. Moreover, the potential and capabilities of new digital institutions are most in demand in Russia, where, on the one hand, there is a fairly high development of new information technologies and, on the other hand, critically low public confidence in the institutions of state power [2].

\section{Materials and Methods}

The methodological basis of our research was a combination of poststructuralism methodol ogy and a set of scientific methods (event analysis, case-study, network analysis, secondary analysis, etc.). Postmodernity is a time of rapid transformations taking place under the technological determinant of the fourth industrial revolution.

Today, network communication is becoming the subject of close attention of researchers. Thus, a significant characteristic of postmodernity in politics is the widespread introduction of networkization technologies. M. Castells was one of the first to foresee these processes, raising the question of the upcoming qualitative transformations of society, as a result of which the structures of industrial modernity will have to give way to network information flows.

Taking as a basis the postmodern concept of communication (R. Barthes, J. Baudrillard), according to which communication is based on the production of signs, Castells comes to the conclusion that, in a sense, all reality is virtual [3].

Here he assigns a special role to the phenomenon of «mass self-communication» as an innovative model of interaction between individuals [4].

J. Urry and E. Elliott analyzed the trend towards a decrease in the size of the gadget required for the implementation of network mobility (miniaturized mobility). Thus, E. Elliott argues that mobile technologies transform the hierarchy of social relations [5].

\section{Results and Discussion}

The digital network society of postmodernity represents a society of a high scientific and technological character in comparison with previous societies. However, the opportunities for upward social mobility in this society are not only not expanding, but rather narrowing. Elite groups are basically preserved and are only partially reformatted in the process of social transformation. Moreover, the transformation covers all spheres of social life.

The digitalization process, on the one hand, significantly expands the boundaries of human potential, but it, in its negative aspect, at the same time, can be an instrument for the implementation of all-pervading control over a person, her total subordination.

In Japan and the United States, big data analysis systems based on artificial intelligence are being introduced into political decision-making processes. Moreover, artificial intelligence helps the Japanese to find a partner to create a family. As part of an experiment in Japan, the neural network participated in the elections as a real candidate. In particular, she answered questions from voters and scored a good result. at first glance, they do not change anything: voters vote for the images of politicians, often without knowing them personally.

Political technologies provide new opportunities for protest actions, when not the politicians themselves, but their holograms, can participate in the actions. However, in the legal field, such actions remain unregulated [6]. Moreover, not only correspondence with the "machine" as with a real person is possible: DeepFake technologies reproduce the voices and 
images of public politicians. The network contains fake speeches of famous politicians who broadcast the meanings the operators need. It is now almost impossible to distinguish the machine and the voice from the real one. The need for a specialist person to organize communication is noticeably reduced.

Digitalization is usually carried out in the context of the historical forms of national political culture. Today, China is the undisputed world leader in digital control, with its own national analogs of world video hosting sites, search engines and social networks operating here, for example: Facebook - Renren; Twitter - Weibo; Google - Baidu; Pinterest - Huaban; YouTube - Youku. Since 2014, the PRC has been running a «social credit» program, in accordance with which, since 2020, the rating system for businesses and individuals has been fully operational. To earn or not to lose points, it is required to comply with the laws, but in addition, the rating is assessed by the moral and ethical appearance of the citizens of the PRC.

For citizens with a high rating, the system provides social and economic benefits, for those with a low rating, there are socio-economic and political and restrictions on rights. These citizens are experiencing employment problems as well as restrictions on government online services and virtual sites.

Within the framework of this system, the PRC has created a modern and largest face recognition system in the world. With the help of a face recognition system combined with geodata, law enforcement agencies efficiently and quickly find criminals. This system covers almost the entire population of China and is able to correctly identify even those individuals whose faces are covered with a medical mask. This system operates more rigidly in the Xinjiang Uygur Autonomous Region, where severe restrictions have been imposed on the Uyghur population. The system of political surveillance of opposition and religious activists is especially developed here. However, in the situation of the coronavirus pandemic, it was digital surveillance technologies that helped China to quite successfully defeat the spread of the infection.

Russia is actively developing a single database for all citizens of Russia. It is assumed that the resource will contain both basic and additional information about any citizen. A single database will accumulate information from disparate registers of state structures: the Ministry of Defense; Ministry of Internal Affairs; The Pension Fund; Ministry of Education and Science; CHI Fund; FTS, etc.

In addition, the Federal Security Service (FSB) and the Foreign Intelligence Service will be able to enter into the database information that was not previously recorded in other state and municipal information resources.

A huge amount of material for analysis is left by users in the digital space: it has been proven that 68 likes of a user on Facebook make it possible to determine a user's skin color, sexual and political orientation with a probability of more than $85 \%$. Users often disclose their personal characteristics themselves. Large IT corporations monetize this information. [7, P.29-70], gain access to information in the minds of users. The latter end up in a «digital isolation», since corporations replace reality with images and events that are harmonious for a person. Targeting of political advertising is carried out not according to social characterist ics (age, employment, income), but pointwise, according to psychotypes. Management beco mes invisible: the average person «runs from freedom», wants Big Data to suggest what to do and how to do it.

The coronavirus pandemic is an important milestone in the development of the tracking and digital control system in Russia, providing state authorities with legal and unprecedente dly broad opportunities to control civil society. At the same time, the epidemic became a test for the tracking system being created in Moscow.

Initially, people who returned from abroad fell into self-isolation. Since mid-March, the Moscow health department began sending them addressed messages and emails demanding to stay at home. By agreement with mobile operators, they began to take control of SIM- 
cards of everyone who returned to Russia during this period. A compulsory self-isolation regime was introduced for the elderly over 65 years of age and those suffering from chronic diseases. On March 29, it was expanded to include all residents of the capital. Then, fines were imposed for violating the self-isolation regime. Then the Moscow application «Social Monitoring» was launched to monitor sick people who were treated at home (in a limited mode, it has been introduced since the beginning of April).

The digital control system was tested and improved, and by the end of the restriction regime, it significantly increased its functionality in the fight against the pandemic, when society suffered «from disinformation related to the coronavirus pandemic» [8]. In all likelihood, methods of digital control over citizens were also recognized as effective. Its key tools, such as a face recognition system, tracking the movements of citizens using geolocation, restricting freedom of speech using the article of the Criminal Code of the Russian Federation on fake news, remained at the government's disposal even after the main quarantine restrictions were lifted.

However, unlike China, Russia demonstrates a critical dependence on foreign technologies and gadgets, which in the context of postmodern network standards can pose threats to the state sovereignty of Russia and, in the long term, contribute to the transformation of our state into a territory coordinated from the outside, available for external control [9]. In this case, it is necessary to take into account the danger of total social exclusion. Since such processes break the usual pace of development of society and the model of socio-political balance, adjusting the long-term prospects and future algorithms of social development.

\section{Conclusions}

Our research shows a significant increase in technological capabilities to control the digital space. In particular, political actions of certain groups of the population in the information space: publications and reposts; expression of approval or condemnation (likes or dislikes), everything based on Big Data technology can be used to monitor the political behavior of an individual and even certain target audiences. Political protests in Russia in 2011-2012 showed that the system was not ready for preventive prevention of protest actions and effective search for their participants. On May 6, 2012, the so-called «March of Millions» took place in Moscow, which ended in riots on Bolotnaya Square. The Investigative Committee has launched a large-scale investigation into a criminal case of riots. More than 30 activists were convicted, but the police were unable to identify the activists whose faces were closed.

Therefore, after the end of the protests in Moscow, a radical introduction of the city video surveillance system began. By 2012, the core of the centralized system was formed. By the beginning of 2019, there were slightly less than 170 thousand cameras in Moscow installed in yards, entrances, parks, schools, clinics, shops, markets, at construction sites, in the offices of executive authorities and other public places.

The pandemic has provided governments with a convenient opportunity to test the digital technology that controls populations. The fear of the virus has virtually negated the public resistance factor. What seemed like an impermissible penetration into private life yesterday, in the context of a pandemic, has become perceived as a means of salvation.

However, Big Data technologies can also be used for other purposes - from fighting crime to spying on «unreliable» persons and political opponents.

Digital technologies have been used for this in the past, but now the scale of their adoption is likely to increase significantly. An illustrative example is Moscow, where, after the recognized successful experience of combating the pandemic, it is planned to expand the network of cameras with face recognition. 
Technologies today do not allow for one hundred percent totalitarian control on a large scale. The Chinese practice of governing Xinjiang Uygur Autonomous Region is the exception rather than the rule. Digital control is also unable to stop truly massive public protests. Nevertheless, as the experience of Russia and China shows, the existing tools are quite enough to track and neutralize specific politicians and activists.

A citizen may not notice the system existing in his city or country until he himself is in the focus of her attention. Therefore, in countries that opt for more control, risks of abuse of access and powers by intelligence agencies inevitably arise, for example, in terms of political surveillance.

The pandemic has significantly shifted the balance between privacy and security in favor of the latter. Therefore, after the end of the pandemic, «post-like» societies will have to look for new mechanisms to curb the state's desire for ubiquitous digital control.

Already, based on the analysis of user accounts, access to individual frames of citizens is being formed. And on their basis, Big Data generates a political technological explanatory model for each specific user. However, the widespread and tatal introduction of such technologies can become a generator of a new form of socio-political deprivation.

Robot programs replace real human communication - with simulacra, based on the use of so-called «digital value-semantic capsules» [10].

Already, digital technologies are creating new risks, threatening the stability of the country's most important political institutions, by replacing them with electronic services, programmable smart contract algorithms and non-falsified blockchain ledgers. In this case, constructive interaction between civil society and government bodies will help to develop scenarios for designing political processes that ensure modernization changes with minimal turbulence in political design.

\section{References}

1. S.V. Biryukov, S.N. Chirun, A.V. Andreev, Tomsk State University Journal of Philosophy, Sociology and Political Science, 59, 199 (2021)

2. M.O. Makusheva, T. A. Nestik, Monitoring of Public Opinion: Economic and Social C hanges, 6, 427 (2020)

3. M. Castells, Information Age: Economy, Society and Culture (2000)

4. M. Castells, The Rise of the Network Society, 1, 624 (2010)

5. A. Elliott, Psychoanalysis, Culture \& Society, 18(1), 71 (2013)

6. S V. Biryukov, M.M. Kislyakov, S.N. Chirun, Tomsk State University Journal of Philosophy, Sociology and Political Science, 50, 168 (2019)

7. D.G. Podvoyskiy, Monitoring of Public Opinion: Economic and Social Changes, 5, 29 (2020)

8. V.V. Vasilkova, N.I. Legostaeva, Monitoring of Public Opinion: Economic and Social Changes, 6, 329 (2020)

9. T.V. Evgenieva, N.V. Smulkina, I. A. Tsymbal, Policy, Political Studies, 4, 181 (2020)

10. S.V. Volodenkov, Bulletin of Tomsk State University, 44, 205 (2018) 